\title{
EDUCAÇÃO A DISTÂNCIA SOB A ÓTICA DA TEORIA GERAL DE SISTEMAS
}

INDAIAL/SC JULHO/2018

\author{
Danice Betania - Uniasselvi - danicebetania@gmail.com \\ Simone Erbs da Costa - Uniasselvi - simoneerbsdacosta@gmail.com \\ Greisse Moser Badalotti - UNIASSELVI - greisse.moser@uniasselvi.com.br
}

Tipo: Investigação Científica (IC)

Natureza: Relatório Final de Pesquisa

Categoria: Conteúdos e Habilidades

Setor Educacional: EDUCAÇÃO SUPERIOR

\begin{abstract}
RESUMO
Como requisito de conclusão do curso de pós-graduação Gestão em Tutoria realizado Centro Universitário Leonardo Da Vinci, partimos como ponto fundamental da nossa discussão o Ensino na modalidade de Educação à Distância (EAD) como sistema educacional, cuja função demonstra possibilidades diversas, de formação e qualificação profissional, além da contribuição social e da interação do aprendizado. O presente artigo tem como objetivo geral: comparar as práticas educacionais na modalidade EAD com a Teoria Geral de Sistemas. Com base nesses pressupostos a metodologia adotada na pesquisa se caracterizou como pesquisa bibliográfica exploratória onde foram caracterizados aspectos que comparam o sistema de modalidade da Educação à distância com a Teoria Geral de Sistema. Ao considerarmos um sistema EAD como sistema aberto, a sua eficácia como um todo é entendida como a capacidade de atender quantitativamente e qualitativamente a determinada necessidade do ambiente sempre mantendo a visão do todo. A totalidade é o ponto vital de qualquer paradigma que surge a partir da visão sistêmica.
\end{abstract}

Palavras-chave: Educação à distância. Sistemas. Teoria Geral de Sistemas 


\section{INTRODUÇÃO}

No contexto da educação escolarizada, o ensino na modalidade de Educação à Distância (EAD) possibilitou que muitos profissionais que estão fora do mercado de trabalho encontrem, nas ferramentas oferecidas por esta modalidade de ensino, uma oportunidade de formação e ou especialização. Para melhor compreender o sistema de ensino na modalidade EAD buscamos a Teoria Geral de Sistemas e neste movimento de descoberta, foi possível entender que um sistema EAD é composto, dentre outros, pelos subsistemas recursos humanos, infraestrutura, conteúdo, tecnologia, ambiente de aprendizado e sistemas avaliativos. Cada subsistema importa e recebe insumos do ambiente como recursos, energia e informação, que lhes proporcionam os meios necessários para seu funcionamento, sendo que a capacidade de adaptação e mudança é uma das principais causas da sobrevivência e da relevância das instituições universitárias hoje (ROSSATO, 2005). Ainda, fundamentados na referida teoria consideramos que os subsistemas são as partes do sistema EAD que interligados processam todas as atividades de ensino que constituem o sistema nas práticas educacionais. A energia, matéria e informação, por exemplo, armazenadas são movimentos que permitem ao sistema o desenvolvimento da sua capacidade de ser e de existir. De acordo com Garbin e Dainese (2010), um sistema pode ser considerado um agrupamento de partes que operam juntas com um propósito comum. Entendem a EAD como um sistema complexo e dinâmico, onde as mudanças não ocorrem de forma isolada, comparamos esse tipo de sistema, como uma teia que possui disposição de tentar alguma forma de equilíbrio e de estabilidade.

Os autores explicam que os sistemas EAD tendem a recuperar seu equilíbrio de alguns pequenos desvios de comportamento, como um organismo vivo, que se recupera de um corte ou de uma doença, ou uma família, que consegue conviver e se manter juntos, mesmo com a ocorrência sucessiva de muitas adversidades. Neste viés, estudos de Morin (2005), destacam que os sistemas não são formados apenas de partes ou de elementos constituintes, mas das atuações e interações entre unidades complexas. Tal concepção, ajuda na compreensão que o conjunto de interações e relações estabelecidas também, podem caracterizar a organização de uma modalidade de ensino a distância. Foi neste movimento que o presente artigo tem como objetivo geral: comparar as práticas educacionais na modalidade EAD com os fundamentos da Teoria Geral de Sistemas. Para atingir este supracitado objetivo é necessário desenvolvermos as seguintes ações: (1) discutir a complexidade que envolve a prática educacional na modalidade EAD; (2) realizar revisão teórica sobre conceitos do Ensino na modalidade EAD; (3) compreender conceitos da teoria geral de sistemas; (4) construir base teórica para atender aos objetivos anteriores na concepção de uma visão sistêmica a partir da 
Teoria Geral dos Sistemas.

Com base nesses pressupostos a metodologia adotada na pesquisa se caracterizou como pesquisa bibliográfica exploratória buscando aspectos que nos ajudam a compreender o sistema de modalidade da Educação à distância por meio dos pressupostos da Teoria Geral de Sistema. Segundo Rauen (2006), a pesquisa bibliográfica ou de referência consiste na busca de informações no acervo bibliográfico, o presente estudo foi desenvolvido a partir de fontes já publicadas, tais como livros, teses e artigos científicos. Entendemos que "são consideradas pesquisas teóricas aquelas que têm por finalidade conhecer ou aprofundar conhecimento e discussão" (BARROS; LEHFELD, 2000, p. 78). Para melhor apreensão organizamos o artigo da seguinte forma, na primeira parte, discutiremos a organização e estrutura de um sistema percebendo que o sistema educacional, constitui-se em um cenário dinâmico. Em seguida, trouxemos a possibilidade de olhar o pensamento sistêmico na educação, como fonte de resposta e ou alternativas aos questionamentos que apresentam características que estão interligados com outros elementos de um sistema maior. Com o intuído de amadurecer essa discussão abordamos brevemente sobre a educação e as práticas educacionais. $\mathrm{E}$, como último tópico apontamos algumas considerações sobre a proposta do presente estudo.

\section{ORGANIZAÇÃO DE UM SISTEMA DE EDUCAÇÃO À DISTÂNCIA}

A modalidade da educação a distância implica na organização e estruturação de um sistema específico composto de elementos importantes para o seu funcionamento. $O$ sistema EAD não pode ser compreendido como um conjunto de partes funcionando isoladamente, mas sim, como uma estrutura complexa onde suas interações originam propriedades, que não são explicáveis pela simples soma das partes (MOORE; KEARSLEY, 2007). As partes então, influenciam-se umas às outras de maneira mútua. Tais fluxos de influência, segundo Senge (1990, p. 82), têm um caráter "recíproco, uma vez que toda e qualquer influência é, ao mesmo tempo, causa e efeito e a influência jamais tem um único sentido", dando origem aos ciclos de causação circular denominado de feedbacks. Neste movimento, destacamos a comunicação como um dos elementos essenciais para funcionamento de um sistema $E A D$, "as relações são o que dá coesão ao sistema todo, conferindo-Ihe um caráter de totalidade ou globalidade, uma das características definidoras do sistema" (VASCONCELLOS, 2008, p.199). Quando pensamos no contexto do ensino a distância a comunicação poderá propiciar oportunidades para o desenvolvimento de projetos compartilhados, para 0 reconhecimento e respeito em relação às diferenças culturais e a (re)elaboração do próprio conhecimento. Em um sistema EAD a interação é fundamental no processo de 
comunicação e deve ser facilitado pelo uso dos meios tecnológicos permitem combinar a flexibilidade da interação humana com a independência no tempo e no espaço (MORIN, 2005).

Faller e Rodrigues (2010), reforçam que no contexto de um sistema EAD, os ambientes de aprendizagem surgem como soluções atraentes, uma vez que oferecem um local que integra um vasto conjunto de funcionalidades, favorecem a flexibilidade dos espaços e os momentos de aprendizagem de forma não linear. Neste tipo de sistema o aluno é considerado o sujeito do processo de ensino-aprendizagem. Pensando em questões como essa o ponto de partida de todo o planejamento do processo de ensino, passam a ser atividades que abrangem vários elementos de um sistema como: aquele que ensina, aquele a quem se ensina e aquilo que o primeiro ensina ao segundo, os conteúdos. Tal conjuntura busca reforçar o compromisso coletivo e conexo, envolve o respeito às identidades e às diversidades como partes equivalentes. Morin (2005), menciona que o ambiente virtual de aprendizagem como um sistema que reúne uma diversidade de recursos e ferramentas, permite potencializar a educação. $O$ ambiente virtual facilita a interação, ao passo que profissionais de diversas regiões do mundo podem se corresponder, ajudando-se mutuamente, respeitando a rotina e a disponibilidade de cada um. Neste viés, estudar a distância não significa que os alunos e os professores fiquem isolados, mas que ampliem suas habilidades, no caso específico dos alunos, dá autonomia e independência nos estudos e no caso dos professores, habilidades de diálogo e motivação para instigar a participação dos alunos. Para melhor compreensão, observamos a figura que ilustra a dinâmica de funcionamento do sistema EAD.

Figura 1- Relação de um sistema EAD com a teoria geral de sistemas

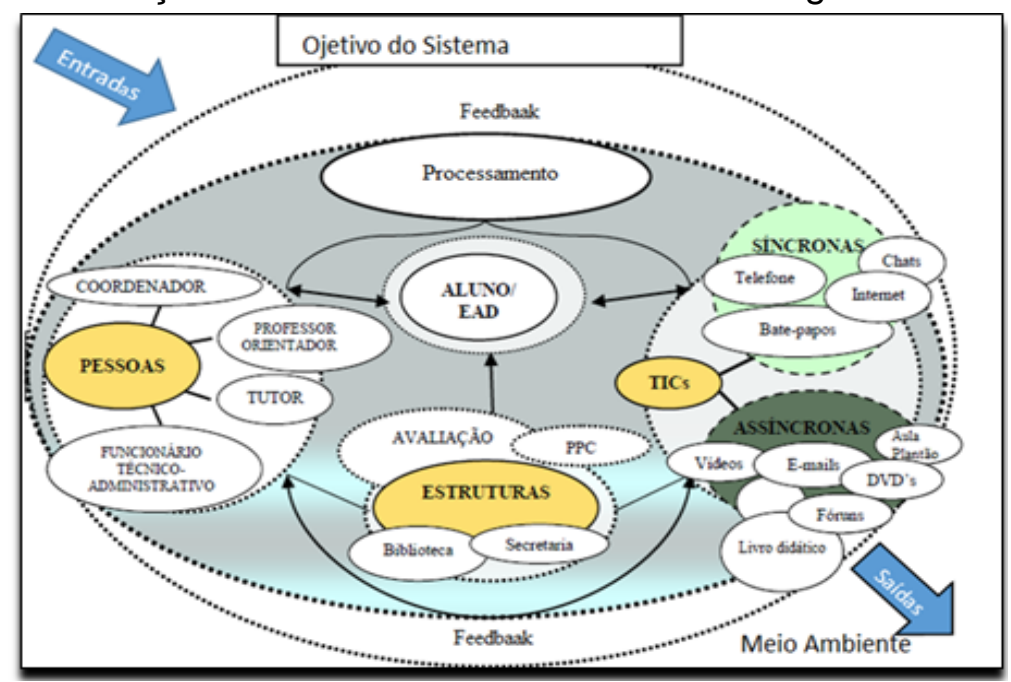

Fonte: adaptado de Faller e Rodrigues (2010, p. 4).

Uma característica da modalidade EAD é o fato do aluno estar diretamente em contato 
com o material didático e incentivado a (re)elaborar seu conhecimento, com apoio da tecnologia. É preciso estimular a (re)construção do conhecimento neste tipo de sistema, interagir o que é explícito e tácito, originando a conversão do conhecimento proposta por Nonaka e Takeuchi (1997), através da socialização e compartilhamento de experiências. Neste processo, os autores descrevem a externalização que é a conversão do conhecimento tácito em explícito, a combinação que é a relação de conhecimento explícito para conhecimento explícito e a internalização, quando ocorre aprendizado após a realização de uma determinada tarefa. Os autores Faller e Rodrigues (2010), reforçam que o sistema EAD é formado por processos e componentes que operam juntos para que ocorra ensino e o aprendizado a distância, tais processos incluem dentre outros, os subsistemas de fontes de informação, transmissão, energia e interação. Sabemos que a informação em qualquer tipo de sistema serve como alicerce para resolução e ou elaboração de um problema. Sendo assim, a comunicação entre os elementos deste processo deve fluir livremente, partindo do mesmo princípio de compartilhamento das experiências e saberes que somente a prática educacional proporciona. Como sistema e subsistemas que interagem, quaisquer alterações ou modificações em uma parte deles, pode exercer efeitos em outras partes dos sistemas e subsistemas interdependentes.

Na concepção de Aretio (1991), EAD é um sistema tecnológico de comunicação intensa e multidirecional, que permite a interação entre professores e alunos por meio da ação sistemática e conjunta de diversos recursos didáticos e do apoio de uma organização tutorial, que propiciam o ensino-aprendizagem de forma autônoma aos estudantes. Em contrapartida, (BARBERÀ, 2006) sinaliza que o ato de aprender e ensinar continuam pondo em jogo os mesmos protagonistas de uma situação presencial, a formação que rodeia a aprendizagem nos moldes $E A D$ não é consequência de nenhuma fórmula mágica nem metodologia extraordinária. De acordo com os autores, o que varia são as proporções de interação e o contexto espaço e tempo que influenciam na ação formativa. Morin (2005) ressalta que é necessário saber que o surgimento de hierarquias dentro de sistema educacional também acontece, onde cada sistema, possui vários subsistemas, assim como pode ser parte de um sistema maior. Há uma organização sistêmica, onde cada envolvido no processo de ensinar e aprender a distância precisa entender sua responsabilidade no sistema, para então, encontrar a devida equanimidade entre seus direitos e deveres. A Instituição de Ensino à distância poderá facilitar o processo ensino-aprendizagem quando desenvolve a cultura de estímulo ao aprendizado, quando supera barreiras e incentiva a aproximação de diferentes grupos podendo alcançar diferentes sistemas, melhorando a comunicação entre eles e o fluxo de informações. 
Sendo assim, compreendemos que os sistemas EAD, são sistemas abertos e apresentam, necessariamente, fronteira permeável ao ambiente, ou seja, existe um movimento de entrada e saída de elementos através destas fronteiras. Recebem do ambiente externo novos elementos de entrada e devolve ao ambiente produtos do sistema de saída. Também, sabemos que em um sistema EAD a estabilidade não é interminável ou infinita, pois a qualquer momento há uma combinação de estados e fluxos que podem levar um sistema além do seu limite, ou seja, a exaustão. Então, para sobreviver é necessário responder eficazmente às pressões exercidas pelas mudanças contínuas e rápidas do ambiente (MOORE; KEARSLEY, 2007). O sistema EAD possui objetivos, metas e finalidades a serem alcançadas. Sendo assim, baseado nos estudos desenvolvidos pelo autor Moore e Kearsley (2007) compreendemos que uma Instituição normalmente é afetada por fatores externos (como regulamentações, concorrência e políticas educacionais), muitos dos quais a organização não pode controlar de maneira direta. Estes fatores então, influenciam o ambiente de um sistema EAD sabendo que o ambiente de um sistema, é o conjunto de elementos que não pertencem ao sistema. Porém, qualquer alteração no sistema pode mudar ou alterar os seus elementos e qualquer alteração nos seus elementos pode mudar ou alterar o sistema. Para tal intento são necessárias práticas bem planejadas e instrumentalizadas. Poucas organizações são capazes de moldar o ambiente externo inteiro com suas ações, tornando necessário seguir um pensamento sistêmico.

\subsection{PENSAMENTO SISTÊMICO NA EDUCAÇÃO}

A importância de olhar o pensamento sistêmico na educação é buscar resposta aos questionamentos que apresentam características que são interdependentes de muitos outros elementos, o que não se limita a uma única área do conhecimento. Formadas por diferentes setores e imersas em um contexto permeado pela globalização, aceleração, mudanças e competitividade as Instituições de Ensino buscam meios eficientes e eficazes de manter os sistemas em equilíbrio (KIM, 1997). O mesmo autor, adverte que apesar de formada por muitos subsistemas, o sistema EAD carece de comunicação, visão sistêmica, dentre outros fatores, para tornar as práticas educacionais viáveis e constantes. As ideias de sistemas tiveram um impacto de tal ordem que, praticamente, afetaram grande parte do conhecimento humano, encontramos referências nas mais variadas áreas de conhecimento da "abordagem sistêmica" ou "enfoque de sistemas". Vasconcellos (2002), por exemplo, avalia o pensamento sistêmico como um conjunto de pressupostos, um novo paradigma para nossas ações no mundo e percebe como semelhantes os conceitos de paradigma, pressuposto epistemológico, premissa e concepção de mundo estão relacionados com o pensamento sistêmico. Neste sentido, o pensamento sistêmico poderá se tornar um fator importante quando estudamos 
sistemas que envolvem a ação humana, incluindo neste caso as Instituições de Ensino onde, os fatores envolvidos podem referir-se as mais variadas formas de informação, em diferentes níveis de investigação.

Então, o pensamento sistêmico é "um fenômeno dentro de um contexto, que estabelece a totalidade das interações envolvidas, em oposição à busca das relações causais simples entre partes isoladas" (CAPRA, 1997, p.39). O pensamento sistêmico na educação, na perspectiva da complexidade segundo Keim (2000, p.64), esta "pautado na organização e não na ordenação". Essa complexidade surge devido as dependências, relações e reflexos que há em cada elemento de uma organização, sabendo que para Morin (2005) a complexidade é o tecido de acontecimentos, ações, interações, decisões e acasos que constitui um ambiente fenomênico. Flood e Carlon (1998), explicam que o pensamento sistêmico é o pensamento voltado para o todo, onde nenhuma ação na educação é empreendida sem considerar seu impacto em outras áreas da organização e da sociedade. Neste viés, a dinâmica da educação deve considerar a liberdade como importante referencial, quando Paulo Freire (1984) menciona a educação explica que "não existe liberdade sem risco, a liberdade deve se apresentar como uma permanente reinvenção do ser humano na aprendizagem de sua autonomia". Relacionando o pensamento de Paulo Freire ao tema de estudo porque pensamos que a autonomia dos educandos se manifesta no contexto EAD pela movimentação dos sujeitos em diferentes espaços, conteúdos, comunidades na construção de seu próprio aprendo. Agregado a tal movimento, temos as tecnologias de informação e comunicação que são subsistema de um sistema maior que oferecem possibilidades para o diálogo.

Para Freire (1984) as tecnologias na educação não são apenas bem-vinda, mas necessárias para o processo de ensino-aprendizagem. É importante atentarmos para a experiência histórica, demonstra que, embora a educação não possa ser reduzida à técnica, também não pode ser feita sem auxílio dela. Visando apoiar a aprendizagem contínua, as tecnologias de informação e comunicação surgem como uma ferramenta fundamental no contexto da modalidade EAD no sentido de auxiliar o processo ensinoaprendizagem. Podendo assim, fornecer os mecanismos e instrumentos necessários para que os alunos sejam capazes de aprender e se desenvolver de acordo com sua capacidade individual e disponibilidade de tempo. O processo ensino-aprendizagem para Morin (2005), é uma unidade dialética entre a instrução e a educação, associada à ideia de que igual característica existe entre ensinar e aprender. O ensino mais especificamente se apresenta como dinâmica que prioriza a ação consciente e referendada em bases comprováveis e em propostas enunciadas com certa objetividade. $O$ ensino nessa perspectiva tem prevalência na epistemologia e nas 
tecnologias e por meio dela, a pessoa se mostra como quem tem conhecimento capaz de desenvolver tarefas e executar processos que carecem de informações claras e objetivas.

Esta relação nos remete a uma concepção de que o processo de ensino-aprendizagem tem uma estrutura e um funcionamento sistêmico, composto por elementos estreitamente inter-relacionados. Para melhor compreendermos Lévy (1999), considera que uma das características do sistema EAD é a influência da organização educacional, envolvendo planejamento, sistematização, prática educacional, projeto e organização dirigida. Na modalidade EAD há sempre uma equipe multidisciplinar elaborando e atualizando materiais para o ensino através de métodos pedagógicos adequados à autoinstrução como também ao treinamento. A instrução como elemento que compõe o sistema é a forma mais simples de sistematizar e formalizar um processo de aprendizagem enquanto, o treinamento visa conduzir o aprendiz na melhora de seu desenvolvimento de competências motoras, cognitivas e interpessoais que contribuem para o alcance dos objetivos organizacionais, de forma planejada e intencional. Mencionamos o treinamento porque discorremos na oferta de cursos na modalidade EAD onde, os serviços de apoio podem ser estruturados com o uso de diferentes mídias. Este tipo de modalidade de educação oferece oportunidades de interação síncrona e assíncrona, e o sucesso para manuseio destas ferramentas dependem do treinamento. Sabendo que no movimento deste sistema é possível alcançarmos a educação, Keim (2000) detalha que a educação centra a formação do ser humano, especificamente a construção da personalidade, enquanto o ensino reflete o processo de otimização da aprendizagem, a qual ajuda na formação do ser humano, mas não o define.

\section{CONSIDERAÇÕES FINAIS}

A Educação é uma proposta que tem como fio condutor alcançar a essência da pessoa, na experiência da educação a distância temos a oportunidade de romper com qualquer tipo de limite. Sinalizamos no presente estudos as tecnologias de informação e comunicação como subsistema de um sistema maior, como possibilidade para o diálogo principalmente, quando tratamos da educação na modalidade à distância. Identificamos a Educação a Distância (EAD), como uma estrutura organizada que objetiva ofertar educação não presencial, ou seja, não é necessário a presença física dos principais atores envolvidos no processo ensino-aprendizagem. Ao analisar um sistema EAD como sistema aberto e dinâmico, a sua eficácia como um todo é entendida como a capacidade de atender quantitativamente e qualitativamente a determinada necessidade do ambiente. As limitações sobre o tema de estudo é manter a visão do todo, canalizando 
todas as forças e energias que ocorrem no sistema para os objetivos preestabelecidos.

Na educação a distância é aconselhável um modelo pedagógico interativo e uma gestão eficaz que possibilitem a participação, a intervenção, a coautoria, a construção e elaboração coletiva do conhecimento e do diálogo entre alunos e professores. Para isso, sugerimos estabelecer sistemas de controle e avaliação, permanentes em todas as fases do sistema visando acompanhar o desempenho do sistema EAD em relação as práticas e aos objetivos educacionais. Ponderamos criar sistemas de retroalimentação, que sejam reintroduções no processo, para que estes não percam o seu movimento dinâmico de interação, para que não haja "estrangulamentos" no sistema, autorregulando assim, todos os subsistemas que compõe uma Instituição de Ensino. Neste artigo abordamos uma educação que opta pela visão sistêmica de ensino em defesa da totalidade, consideramos o sistema EAD como ativo e sua interação se dá em conexão com outros elementos, determinados pela dinâmica do todo. Recomendamos que não seria pertinente que as partes que compõem esse sistema fossem compreendidas como sendo entidades isoladas. Sendo assim, o sistema quando está interligado e ajustado, aponta que qualquer intervenção em uma de suas variáveis tende a acender um efeito no todo.

Atendemos o sistema EAD como uma unidade que resulta da diversidade produzida a partir da existência da unidade ou das partes múltiplas em interação, então os sistemas funcionam como um todo coeso e mudanças em uma das partes provocam mudanças no todo. A totalidade é o ponto vital de qualquer modelo que surge a partir do pensamento sistêmico, que permite romper as barreiras funcionais e visões compartimentadas principalmente quando nos referimos a educação. A educação a distância é considerada um sistema no qual interagem os elementos necessários para que se desenvolva integralmente o processo de ensino-aprendizagem. Neste contexto, 0 ambiente globalizado vem exigindo que as instituições de Ensino apresentem práticas educacionais que despontem uma continuidade dos seus trabalhos, de modo a propiciar perspectivas profissionais aos acadêmicos e crescimento intelectual para todos que a fazem podendo ser um dos seus objetivos de existir.

\section{REFERÊNCIA}

ARETIO, L. G. La educación a distancia: de la teoría a la prática. $2^{\mathrm{a}}$. ed. Barcelona: Editorial Ariel, 2002.

BARBERÁ, E. ROMISZOWSKI. Educación aberta y a distancia. Barcelona: Editorial UOC, 2006.

CAPRA, F. A teia da vida: uma nova compreensão científica dos sistemas vivos. 
São Paulo: Cultrix, 1997.

D’AMBRÓSIO, Ubiratan. Educação para uma sociedade em transição. Campinas, SP: Papirus, 1999.

FALLER, Lisiane Pellini; RODRIGUES, Cláudia M. C. Proposta de Instrumento para Avaliação de cursos de ensino a distância. Enegep, 2010.

FLOOD Robert L. \& CARLSON, Ewart R. Dealing With Complexity: $\mathbf{N a}_{\text {introduction }}$ to the Theory and applications of systems Science. Plenum Press, New York, 1988.

FREIRE, P. Educação como prática da liberdade. Rio de Janeiro: Paz e Terra, 1984.

GARBIN, T.R.; DAINESE, C.A. Complexidade da Gestão em EaD. In: 16‥ CIAED Congresso Internacional ABED de Educação a Distância. Ouro Preto: ABED/FGV, 2010. KIM, Daniel H. Systems Thinking Tools: A user reference guide. Combridge, Pegasus Comunicatins Inc., 1997.

KEIM, E. J. Educação, meio ambiente e vida - uma abordagem avaliativa, complexa e transdisciplinar. Educação e Ensino. USF, Bragança Paulista, julho/dezembro 2000, v.5 n.

LÉVY, P. Cibercultura. Rio de janeiro: 1999.

MILLER, D. Environmental Fit and Internal Fit. Organization Science, vol.3, nํ2, May, 1992.

MOORE, Michael G., KEARSLEY, Greg (tradução Roberto Galman). Educação a Distância: uma visão integrada. São Paulo: Ed. Thomson Learning, 2007.

MORIN, Edgar. Introdução ao pensamento complexo. Porto Alegre: Sulina, 2005. ROSSATO, R. Universidade: nove séculos de história. 2. ed. Passo Fundo: Ed. UPF, 2005.

VASCONCELLOS, Maria José Esteves de. Pensamento sistêmico: O novo paradigma da ciência. Campinas, SP:Papirus, 2002. 